\title{
Usefulness of five-item and three-item Mental Health Inventories to screen for depressive symptoms in the general population of Japan Shin Yamazaki*1, Shunichi Fukuhara ${ }^{\dagger 2}$ and Joseph Green ${ }^{\dagger 3}$
}

\author{
Address: ${ }^{1}$ Epidemiology and Exposure Assessment Section, National Institute for Environmental Studies, Tsukuba, Japan, ${ }^{2}$ Department of \\ Epidemiology and Healthcare Research, Graduate School of Medicine and Public Health, Kyoto University, Kyoto, Japan and ${ }^{3}$ Office of \\ International Academic Affairs, Graduate School of Medicine, University of Tokyo, Japan \\ Email: Shin Yamazaki* - yamazaki.shin@nies.go.jp; Shunichi Fukuhara - fukuhara@pbh.med.kyoto-u.ac.jp; Joseph Green - jgreen@m.u- \\ tokyo.ac.jp \\ * Corresponding author †Equal contributors
}

Published: 08 August 2005

Health and Quality of Life Outcomes 2005, 3:48 doi:10.1 I86/1477-7525-3-

48

This article is available from: http://www.hqlo.com/content/3///48

This is an Open Access article distributed under the terms of the Creative Commons Attribution License (http://creativecommons.org/licenses/by/2.0), which permits unrestricted use, distribution, and reproduction in any medium, provided the original work is properly cited.

\begin{abstract}
Background: The five-question Mental Health Inventory (MHI-5) is a brief questionnaire that can be used to screen for depressive symptoms. Removing the 2 anxiety-related items from the MHI5 yields the MHI- 3 . We assessed the performance of the Japanese versions of the MHI- 5 and $\mathrm{MHI}-$ 3 in detecting depressive symptoms in the general population of Japan.

Methods: From the population of Japan, 4500 people 16 years old or older were selected by stratified-random sampling. The Medical Outcomes Study 36-Item Short Form Health Survey (SF36, which includes the MHI-5) and the Zung Self-rating Depression Scale (ZSDS) were included in a self-administered questionnaire. ZSDS scores of 48 and above were taken to indicate the presence of moderate or severe depressive symptoms, and scores of 56 and above were taken to indicate the presence of severe depressive symptoms. We computed the correlation coefficient between the ZSDS score and the scores on the MHI-5 and MHI-3. We also computed the sensitivity, specificity, and area under the receiver operating characteristic (ROC) curve.

Results: Of the 3107 subjects (69\% of the 4500 initially selected), $14.0 \%$ had moderate or severe depressive symptoms, and $2.0 \%$ had severe depressive symptoms as measured with the ZSDS. The correlations of ZSDS scores with MHI- 5 scores and with MHI- 3 scores were similar: -0.63 and $0.6 \mathrm{I}$, respectively. These correlation coefficients were almost the same whether or not the data were stratified by age and sex. For detecting severe depressive symptoms with the MHI-5, the area under the ROC curve was 0.942 ( $95 \% \mathrm{Cl}: 0.919-0.965)$; for the $\mathrm{MHI}-3$, it was 0.933 ( $95 \% \mathrm{Cl}: 0.904$ -0.962 ).
\end{abstract}

Conclusion: The MHI-5 and MHI-3 scores were correlated with the ZSDS score, and can be used to identify people with depressive symptoms in the general population of Japan.

\section{Background}

Depression disorders are a major health problem in Japan. Depressive mood is associated with suicide in mid- dle-aged workers [1], and the number of suicides has increased as economic conditions have worsened since 1998 [2]. Nonetheless, there are few studies of the 
prevalence of depression or of depressive symptoms in communities in Japan $[3,4]$.

To assist in detecting depression or depressive symptoms, many screening questionnaires have been developed. Some of these have 20 to 30 items, take only a few minutes to complete, use the number of symptoms as the score, and have good performance to detect depressive state. Instruments that are even shorter but nonetheless have good performance to detect depressive state have also been developed [5-7]. One such questionnaire is the five-item version of the Mental Health Inventory (MHI-5) $[6,7]$. The MHI-5 is used as the "Mental Health" domain of the Medical Outcomes Study 36-Item Short Form Health Survey (SF-36). The SF-36 has been translated into Japanese [8], and the Japanese version has been validated for use in the general population of Japan [9], but the performance of the MHI-5 has not been evaluated in detail. In addition, two of the items in the MHI-5 are almost identical to two items in a scale developed to measure anxiety [10]. We hypothesized that removing those two anxiety-related items would result in a scale (the MHI-3) that performs as well as the MHI-5 in detecting symptoms of depression.

In this study, we compared the Japanese version of the MHI-5 and MHI-3 to the 20-item Zung Self-rating Depression Scale (ZSDS) [11], and assessed the performance of the Japanese versions of the MHI-5 and MHI-3 in detecting depressive symptoms among the general population.

\section{Methods}

\section{Setting and participants}

We used data that had been collected previously for a study of the validity of the Japanese version of the SF-36, and calculated national norm scores of all subscales of the SF-36 $[8,9]$. Details of the nationwide survey have been described previously [9]. Briefly, a total of 4500 people 16 years old or older were selected from the entire population of Japan by stratified-random sampling in 1995. A self-administered questionnaire was mailed, and the subjects were visited to collect the questionnaires. The SF-36, the ZSDS [11] (described below), and questions about demographic characteristics were included in the questionnaire.

The ZSDS consists of 10 positively worded items and 10 negatively worded items asking about symptoms of depression. Several studies have established the ZSDS as a reliable and valid instrument for measuring depressive symptoms [12-14]. The ZSDS scores were used to define four categories of the severity of depression: within normal range or no significant psychopathology (below 40 points); presence of minimal to mild depression (40-47 points); moderate to marked depression (48-55 points); presence of severe to extreme depression (56 points and above). These score ranges result from the studies of Zung [15] and Barrett et al [16]. The ZSDS has been translated into Japanese and studies of the validity of the Japanese version have been published [17]. Because the ZSDS is not a clinical diagnostic tool, subjects with high scores are said to have depressive symptoms rather than "depression."

Like the rest of the SF-36, the MHI-5 was administered as a paper-and-pencil questionnaire. The instrument contains the following questions: 'How much of the time during the last month have you: (i) been a very nervous person?; (ii) felt downhearted and blue?; (iii) felt calm and peaceful?; (iv) felt so down in the dumps that nothing could cheer you up?; and (v) been a happy person?' For each question the subjects were asked to choose one of the following responses: all of the time (1 point), most of the time ( 2 points), a good bit of the time ( 3 points), some of the time ( 4 points), a little of the time ( 5 points), or none of the time ( 6 points). Because items (iii) and (v) ask about positive feelings, their scoring was reversed. The score for the MHI- 5 was computed by summing the scores of each question item and then transforming the raw scores to a 0-100-point scale [18].

Items (i) and (iii) are almost identical to 2 items in the Zung Self-rating Anxiety Scale [10]. To make a scale that is even shorter than the MHI-5 and is focused on depression we removed those two anxiety-related items. Thus, the MHI-3 comprised only (ii), (iv), and (v) above. Possible scores on the MHI-3 ranged from 3 to 18 points.

\section{Statistical methods}

First, we computed the correlation coefficient (Pearson's) between the ZSDS scores and the scores on the MHI- 5 and the MHI-3. We computed the sensitivity, specificity, and area under the receiver operating characteristic (ROC) curve. Analysis of ROC curves has been described in detail and ROC analysis is used extensively in health-related diagnostics $[19,20]$. ROC analysis can be used to study the performance of diagnostic or screening tests across a wide range of sensitivities and specificities. For example, it can be used to compute the sensitivity (the true-positive rate) and specificity (the true-negative rate) for any specified test score. The area under the ROC curve (AUC) is an index of the amount of information the test provides over its entire scoring range $[21,22]$. In general, an AUC can range from 0.5 , which indicates a test with no information, to 1.0, which indicates a perfect test. The "gold standard" criteria for diagnosing depression are considered to be those of the Diagnostic and Statistical Manual of Mental Disorders (DSM) [7]. In this study, because we could not interview all subjects, we used, instead, scores on the ZSDS. For each of the three categories of the severity of depressive states (ZSDS scores of 40 or higher), we 
Table I: MHI-5 scores by demographic categories

\begin{tabular}{|c|c|c|}
\hline & $\begin{array}{c}N(\%) \\
3107(100)\end{array}$ & $\begin{array}{c}\text { Score of the MHI-5 } \\
\text { Mean (SD) }\end{array}$ \\
\hline \multicolumn{3}{|l|}{ Sex } \\
\hline Male & $1573(5 \mid)$ & $73.31(18.63)$ \\
\hline Female & $1534(49)$ & $72.32(19.55)$ \\
\hline \multicolumn{3}{|l|}{ Age (years) } \\
\hline$<30$ & $619(20)$ & $70.17(18.47)$ \\
\hline $30-39$ & $506(16)$ & $72.50(17.47)$ \\
\hline $40-49$ & $665(21)$ & $72.38(20.28)$ \\
\hline $50-59$ & $617(20)$ & $74.22(18.60)$ \\
\hline $60-69$ & $479(15)$ & $75.21(19.11)$ \\
\hline$\geq 70$ & $221(7)$ & $73.23(21.09)$ \\
\hline \multicolumn{3}{|l|}{ Annual household income (million yen) } \\
\hline$<3$ & $385(12)$ & $69.37(20.83)$ \\
\hline $3-4.9$ & $670(22)$ & $71.87(19.08)$ \\
\hline $5-6.9$ & $685(22)$ & $72.62(19.38)$ \\
\hline $7-9.9$ & $648(21)$ & 73.72 ( 18.27$)$ \\
\hline $10-11.9$ & $228(7)$ & 74.57 (18.78) \\
\hline$\geq 12$ & $266(9)$ & $76.63(16.72)$ \\
\hline Missing values & $225(7)$ & $73.30(19.4)$ \\
\hline \multicolumn{3}{|l|}{ Schooling } \\
\hline Junior high school & $613(20)$ & $72.64(19.88)$ \\
\hline High school & $1426(46)$ & $72.97(18.88)$ \\
\hline Junior college, college, or higher & $1028(33)$ & $72.84(18.85)$ \\
\hline Missing values & 40 (I) & $69.95(20.88)$ \\
\hline \multicolumn{3}{|l|}{ Marital status } \\
\hline Single & $622(20)$ & $70.04(18.89)$ \\
\hline Married & $2227(72)$ & $73.74(18.8)$ \\
\hline Separated & $28(\mathrm{I})$ & $75.43(16.86)$ \\
\hline Divorced & $65(2)$ & $68.66(20.91)$ \\
\hline Widowed & $152(5)$ & 72.18 (22.27) \\
\hline Missing values & $13(0)$ & $70.00(19.71)$ \\
\hline \multicolumn{3}{|l|}{ Occupational status } \\
\hline Full time worker & $1610(52)$ & $73.05(18.25)$ \\
\hline Part time worker & $299(10)$ & $74.27(17.96)$ \\
\hline Retired & $164(5)$ & $72.51(22.74)$ \\
\hline Unemployed & $|7|(6)$ & $69.34(21.95)$ \\
\hline Homemaker & $533(17)$ & $73.06(19.71)$ \\
\hline Student & $226(7)$ & 73.36 ( 18.77$)$ \\
\hline Other & $83(3)$ & $68.48(21.49)$ \\
\hline Missing values & $21(I)$ & $70.86(16.64)$ \\
\hline
\end{tabular}

computed the AUC of each of the five items, the MHI-5, and the MHI-3. To define the cut-off points, we first considered each of the actually measured MHI-5 scores as a possible cut-off point. For each score, we took the sum of the sensitivity and the specificity. The score with the highest sum was used as the cut-off point. One cut-off point was determined for each of the three levels of severity defined by ZSDS scores (mild, moderate, and severe).

\section{Results}

The nationwide survey targeted 4500 people, and 3395 (male: 1704; female: 1691) responded to the questionnaire (75\% response rate). Of these 3395 individuals,
3107 (male: 1573; female: 1534) completed all of the items on the ZSDS. The mean score on the MHI-5 was 72.8 (SD = 19.1). The mean scores on the MHI-5 for respondents of different demographic categories are shown in Table 1 . These mean scores ranged from 68.5 to 76.6. Almost $23 \%$ of the respondents had ZSDS scores indicating mild depressive symptoms, $12 \%$ had scores indicating moderate depressive symptoms, and $2 \%$ had scores indicating severe depressive symptoms.

The correlations of ZSDS scores with MHI-5 scores and with MHI-3 scores were similar: -0.63 and -0.61 , respectively. These correlation coefficients were almost 
Table 2: Correlations of ZSDS scores with MHI-5 and MHI-3 scores, by demographic category

\begin{tabular}{|c|c|c|}
\hline & MHI-5 & $\mathrm{MHI}-3$ \\
\hline All & -0.634 & -0.614 \\
\hline \multicolumn{3}{|l|}{ Sex } \\
\hline Male & -0.634 & -0.610 \\
\hline Female & -0.635 & -0.618 \\
\hline \multicolumn{3}{|l|}{ Age (years) } \\
\hline$<30$ & -0.653 & -0.643 \\
\hline $30-39$ & -0.686 & -0.685 \\
\hline $40-49$ & -0.619 & -0.591 \\
\hline $50-59$ & -0.576 & -0.549 \\
\hline $60-69$ & -0.635 & -0.608 \\
\hline$\geq 70$ & -0.698 & -0.671 \\
\hline \multicolumn{3}{|l|}{ Annual household income (million yen) } \\
\hline$<3$ & -0.666 & -0.638 \\
\hline $3-4.9$ & -0.612 & -0.596 \\
\hline $5-6.9$ & -0.642 & -0.642 \\
\hline $7-9.9$ & -0.637 & -0.602 \\
\hline $10-11.9$ & -0.654 & -0.642 \\
\hline$\geq 12$ & -0.562 & -0.554 \\
\hline Missing values & -0.613 & -0.551 \\
\hline \multicolumn{3}{|l|}{ Schooling } \\
\hline Junior high school & -0.612 & -0.579 \\
\hline High school & -0.637 & -0.617 \\
\hline Junior college, college, or higher & -0.651 & -0.636 \\
\hline Missing values & & . \\
\hline \multicolumn{3}{|l|}{ Marital status } \\
\hline Single & -0.661 & -0.638 \\
\hline Married & -0.624 & -0.602 \\
\hline Separated & . & . \\
\hline Divorced & . & . \\
\hline Widowed & -0.658 & -0.642 \\
\hline Missing values & & . \\
\hline \multicolumn{3}{|l|}{ Occupational status } \\
\hline Full time worker & -0.618 & -0.601 \\
\hline Part time worker & -0.533 & -0.509 \\
\hline Retired & -0.741 & -0.711 \\
\hline Unemployed & $-0.7 \mid 4$ & -0.692 \\
\hline Homemaker & -0.646 & -0.636 \\
\hline Student & -0.680 & -0.646 \\
\hline Other & . & . \\
\hline Missing values & . & . \\
\hline
\end{tabular}

the same whether or not the data were stratified by age and sex (Table 2).

With ZSDS scores as the basis for classifying depressive symptoms, ROC analysis allowed us to evaluate the performance of the MHI-5 and the MHI-3. The AUC values are shown in Table 3, and other performance characteristics are shown in Table 4 . We also evaluated the performance of each of the MHI-5 question items individually (Table 3). For the individual items, the range of "cut-off scores" was determined by the range of each question's response options: from "none of the time" to "all of the time." The best-performing item for detecting severe depressive symptoms was the one asking about the frequency of "feeling downhearted and blue". That item had a sensitivity of 0.88 and a specificity of 0.77 (based on a score of 4 points or less). The AUC of the MHI- 3 was only slightly lower than that of the MHI-5 (Figure 1).

Using the MHI-5, the prevalence of severe depressive symptoms (cut-off: 52 points) was $17 \%$, that of moderate or severe depressive symptoms (cut-off: 60 points) was $28 \%$, and that of mild, moderate, or severe depressive symptoms (cut-off: 68 points) was $40 \%$. 
Table 3: ROC analysis of individual MHI-5 items, the whole MHI-5, and the MHI-3, by severity of depressive symptoms

\begin{tabular}{|c|c|c|c|c|c|c|}
\hline \multirow[t]{3}{*}{ Items and scales } & \multicolumn{6}{|c|}{ Severity of depressive symptom (range of ZSDS scores) } \\
\hline & \multicolumn{2}{|c|}{$\begin{array}{c}\text { Mild, moderate, or severe } \\
\text { (40 through } 80)\end{array}$} & \multicolumn{2}{|c|}{$\begin{array}{c}\text { Either moderate or severe } \\
\text { (48 through } 80)\end{array}$} & \multicolumn{2}{|c|}{$\begin{array}{c}\text { Severe }( \\
56 \text { through } 80)\end{array}$} \\
\hline & AUC & $(95 \% \mathrm{Cl})$ & AUC & $(95 \% \mathrm{Cl})$ & AUC & $(95 \% \mathrm{Cl})$ \\
\hline (i) Nervous person & 0.696 & $(0.677-0.716)$ & 0.707 & $(0.680-0.734)$ & 0.826 & $(0.774-0.879)$ \\
\hline (ii) Down in the dumps & 0.713 & $(0.694-0.733)$ & 0.741 & $(0.714-0.769)$ & 0.862 & $(0.813-0.910)$ \\
\hline (iii) Calm and peaceful & 0.745 & $(0.726-0.764)$ & 0.755 & $(0.728-0.782)$ & 0.845 & $(0.797-0.892)$ \\
\hline (iv) Downhearted and blue & 0.739 & $(0.720-0.758)$ & 0.748 & $(0.721-0.776)$ & 0.898 & $(0.855-0.941)$ \\
\hline (v) Happy person & 0.747 & $(0.729-0.765)$ & 0.738 & $(0.711-0.765)$ & 0.858 & $(0.8 \mathrm{II}-0.905)$ \\
\hline MHI-5* & 0.810 & $(0.793-0.826)$ & 0.819 & $(0.795-0.843)$ & 0.942 & $(0.919-0.965)$ \\
\hline MHI-3† & 0.800 & $(0.783-0.817)$ & 0.803 & $(0.779-0.828)$ & 0.933 & (0.904-0.962) \\
\hline
\end{tabular}

Values shown are areas under the ROC curves (AUC), and their $95 \% \mathrm{Cls}$, for three levels of depressive symptoms as measured by ZSDS scores.

*The MHI-5 includes all 5 items. $†$ The $\mathrm{MHI}-3$ includes only items ii, iv, and v.

Table 4: Performance of the MHI-5 and MHI-3 for detecting depressive symptoms

\begin{tabular}{|c|c|c|c|c|c|c|}
\hline \multirow{3}{*}{$\begin{array}{l}\text { Prevalence } \\
\text { Instrument }\end{array}$} & \multirow{2}{*}{\multicolumn{2}{|c|}{$\begin{array}{l}\text { Mild, moderate, or severe depressive } \\
\text { symptoms } \\
\text { (ZSDS scores of } 40 \text { or higher) } \\
37 \%\end{array}$}} & \multirow{2}{*}{\multicolumn{2}{|c|}{$\begin{array}{c}\text { Moderate or severe depressive } \\
\text { symptoms } \\
\text { (ZSDS scores of } 48 \text { or higher) } \\
14 \%\end{array}$}} & \multicolumn{2}{|c|}{$\begin{array}{l}\text { Severe depressive symptoms } \\
\text { (ZSDS scores of } 56 \text { or higher) }\end{array}$} \\
\hline & & & & & & \\
\hline & MHI-5 & MHI-3 & MHI-5 & MHI-3 & MHI-5 & MHI-3 \\
\hline (cut-off score) & $(68)$ & $(14)$ & $(60)$ & $(13)$ & $(52)$ & (II) \\
\hline Sensitivity & $71.5 \%$ & $76.4 \%$ & $74.7 \%$ & $77.1 \%$ & $91.8 \%$ & $90.0 \%$ \\
\hline Specificity & $79.1 \%$ & $71.1 \%$ & $80.0 \%$ & $71.8 \%$ & $84.6 \%$ & $84.2 \%$ \\
\hline Positive predictive value & $66.7 \%$ & $60.8 \%$ & $37.1 \%$ & $30.8 \%$ & $10.8 \%$ & $10.4 \%$ \\
\hline Negative predictive value & $82.5 \%$ & $83.7 \%$ & $95.1 \%$ & $95.1 \%$ & $99.8 \%$ & $99.8 \%$ \\
\hline
\end{tabular}

\section{Discussion}

These data show that the MHI-5 and MHI-3 scores were each correlated with the ZSDS score and had good screening accordance with the ZSDS in the general population of Japan. We also found that the MHI-3 performs almost as well as the MHI-5. The best-performing single item was the one asking about "feeling downhearted and blue," which was also the case in the US [6]. The usefulness of the MHI-5 is consistent with results of a study done in the US [6]. Each scale and each item performed best as a detector of severe depressive symptoms, but each also contributed some information even for detecting moderate and mild depressive symptoms (Table 3 ). Both scales performed better than did any item alone.

Because prevalence affects positive predictive value, the latter was lowest for severe depressive symptoms and was highest for mild, moderate, and severe depressive symptoms (Table 4). For all levels of symptom severity, the positive predictive values of the MHI-3 were similar to those of the MHI-5, and for severe depressive symptoms they were nearly identical (10.8\% and $10.4 \%$ ) (Table 4 ).

A previous study showed that the prevalence of mood disorders (major depression, bipolar disorders, and dysthymia) as measured using the DSM criteria in Japanese people 20 years old and older was 3.1\% [4]. On the other hand, $37 \%$ of the sample in the present study had mild, moderate, or severe depressive symptoms as measured using the ZSDS. People in whom depression is diagnosed using the DSM criteria are probably only a small number of those who report at least some depressive symptoms. In a previous study that also used the ZSDS, the prevalence of mild depressive symptoms among Japanese male workers was $45 \%$ [23], which is similar to that in our study. 


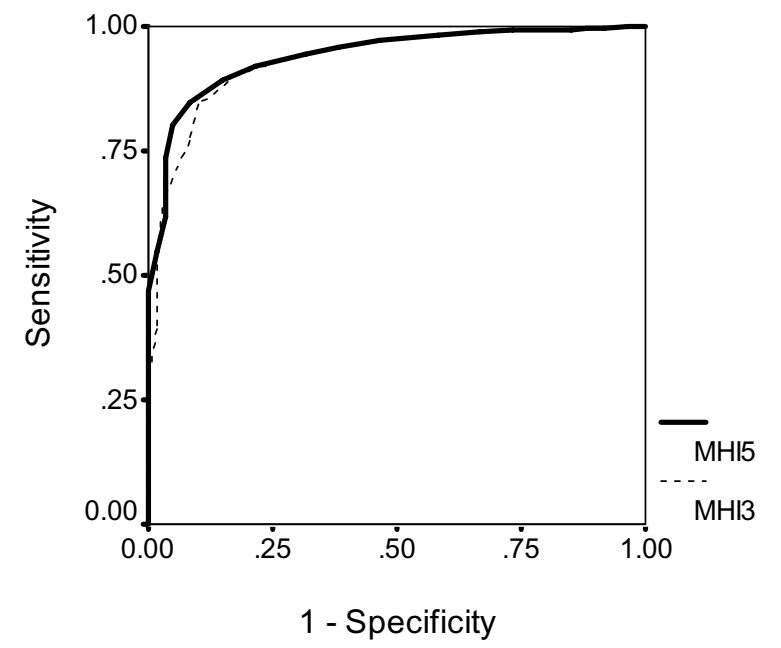

Figure I

ROC curves of the MHI-5 and MHI-3 for detecting severe depressive symptoms (ZSDS above 55).

In addition to its performance as shown in the present ROC analysis, an advantage of the MHI- 5 may be the fact that it is part of the SF-36. The reason is that the possibility of a Hawthorne-type effect (i.e. an effect on study participants that results from their knowing that they are being studied) can be an obstacle to screening for depressive state. Specifically, the subjects' responses on a mentalhealth screening instrument may be affected by their knowledge that they are subjects in a study of mental health. Embedding the mental-health screening instrument in a more general survey, as the MHI- 5 is embedded in the SF-36, could help minimize any such effect.

While the results of this study may be useful for publichealth purposes, surveys done in primary-care settings could provide information that is more directly applicable to clinical work. Also, it should be kept in mind that ZSDS scores alone cannot be used to diagnose clinical depression. Studies using psychiatrist-diagnosed depression in addition to ZSDS scores would provide further information about the utility of the Japanese version of the MHI5.

Another limitation is that the data set was obtained from a 1995 survey. Further studies are needed to confirm the performance of the MHI-5 and MHI-3 using data obtained in recent years.

In conclusion, the MHI- 5 and MHI- 3 scores were correlated with the ZSDS score, and can be used to identify peo- ple with depressive symptoms in the general population of Japan.

\section{List of abbreviations}

AUC: area under the ROC curve; MHI-5: the five-item version of the Mental Health Inventory; MHI-3: those 3 of the MHI-5 questions that were thought to be most directly related to depression; ROC: receiver operating characteristic; SF-36: the Medical Outcomes Study 36-Item Short Form Health Survey; ZSDS: the Zung Self-rating Depression Scale.

\section{Authors' contributions}

SY: analysis of the data, interpretation of results, manuscript writing; SF: initiation and study design, supervision, collection of data; JG: supervision, interpretation of results, manuscript writing.

\section{References}

I. Tamakoshi A, Ohno Y, Aoki K, Hamajima N, Wada M, Kawamura T, Wakai K, Lin YS: Depressive mood and suicide among middleaged workers: findings from a prospective cohort study in Nagoya, Japan. J Epidemiol 2000, 10:173-178.

2. Lamar J: Suicides in Japan reach a record high. BMJ 2000, $321: 528$.

3. Kawakami N, Shimizu H, Haratani T, Iwata N, Kitamura T: Lifetime and 6-month prevalence of DSM-III-R psychiatric disorders in an urban community in Japan. Psychiatry Res 2004, I 2 |:293-30 I.

4. The WHO World Mental Health Survey Consortium: Prevalence, severity, and unmet need for treatment of mental disorders in the World Health Organization World Mental Health Surveys. JAMA 2004, 29 I:258I-2590.

5. Whooley MA, Avins AL, Miranda J, Browner WS: Case-finding instruments for depression. Two questions are as good as many. J Gen Intern Med 1997, I 2:439-445.

6. Berwick DM, Murphy JM, Goldman PA, Ware JE Jr, Barsky AJ, Weinstein MC: Performance of a five-item mental health screening test. Med Care 1991, 29:169-176.

7. Rumpf HJ, Meyer C, Hapke U, John U: Screening for mental health: validity of the MHI-5 using DSM-IV Axis I psychiatric disorders as gold standard. Psychiatry Res 200I, I 05:243-253.

8. Fukuhara S, Bito S, Green J, Hsiao A, Kurokawa K: Translation, adaptation, and validation of the SF-36 Health Survey for use in Japan. J Clin Epidemiol 1998, 5 I: 1037-1044.

9. Fukuhara S, Ware JE Jr, Kosinski M, Wada S, Gandek B: Psychometric and clinical tests of validity of the Japanese SF-36 Health Survey. I Clin Epidemiol 1998, 5 I: 1045-1053.

10. Zung WW: A rating instrument for anxiety disorders. Psychosomatics 1971, 1 2:371-379.

II. Zung WWK: A Self-Rating Depression Scale. Arch Gen Psychiatry 1965, I 2:63-70.

12. Biggs JT, Wylie LT, Ziegler VE: Validity of the Zung Self-rating Depression Scale. Br J Psychiatry 1978, 32:38I-385.

13. Gabrys JB, Peters K: Reliability, discriminant and predictive validity of the Zung Self-rating Depression Scale. Psycholog Reports 1985, 57:1091-1096.

14. Agrell B, Dehlin O: Comparison of six depressive rating scales in geriatric stroke patients. Stroke 1989, 20:1990-1994.

15. Zung WWK: From art to science. Arch Gen Psychiatry 1973, 29:328-337.

16. Barrett J, Hurst MW, DiScala C, Rose RM: Prevalence of depression over a I 2-month period in a nonpatient population. Arch Gen Psychiatry 1978, 35:74 I-744.

17. Fukuda K, Kobayashi S: A study on a self-rating depression scale. Seishin Shinkeigaku Zasshi 1973, 75:673-679. (in Japanese)

18. Ware JE, Snow KK, Kosinski M, Gandek B: SF-36 health survey manual \& interpretation guide Boston, New England Medical Center; 1993. 
19. Metz CE: Basic principles of ROC analysis. Semin Nucl Med 1978 , 8:283-298.

20. Swets JA, Pickett RM, Whitehead SF, Getty DJ, Schnur JA, Swets JB, Freeman BA: Assessment of diagnostic technologies. Science 1979, 205:753-759.

21. Hanley JA, McNeil BJ: The meaning and use of the area under a receiver operating characteristic (ROC) curve. Radiology 1982, 143:29-36.

22. Hanley JA, McNeil B]: A method of comparing the areas under receiver operating characteristic curves derived from the same cases. Radiology 1983, 148:839-843.

23. Kawakami N, Takatsuka N, Shimizu H, Ishibashi H: Depressive symptoms and occurrence of type 2 diabetes among Japanese men. Diabetes Care 1999, 22:107|-6.

Publish with Bio Med Central and every scientist can read your work free of charge

"BioMed Central will be the most significant development for disseminating the results of biomedical research in our lifetime. "

Sir Paul Nurse, Cancer Research UK

Your research papers will be:

- available free of charge to the entire biomedical community

- peer reviewed and published immediately upon acceptance

- cited in PubMed and archived on PubMed Central

- yours - you keep the copyright

Submit your manuscript here:

http://www.biomedcentral.com/info/publishing_adv.asp 